\title{
Analysis of Trends of Fever in the Field Practice Area of a Tertiary Care Hospital, Bengaluru: A Retrospective Data Review
}

\author{
Krithika Talari Thyagaraj ${ }^{1}$, Balwant Singh Patle ${ }^{2}$, Shyam $\mathrm{AC}^{3}$, Vidusha $\mathrm{K}^{4}$, Chandrakala $\mathrm{M}^{5}$
}

\begin{abstract}
Background: Fever is the most common presentation of vector-borne diseases. Fever of undetermined origin is also most often caused by an unusual manifestation of a common disease and is a huge public health problem affecting most people in the developing world. Primary objective of this study was to study the seasonal variations and trend analysis of patients with fever in a rural health training center of a tertiary care hospital in South Bengaluru, Karnataka.

Materials and methods: A retrospective descriptive record-based analysis of patients with fever was conducted in a rural health training center of a tertiary care hospital, Bengaluru, from January 2019 to September 2019. The trends of fever were analyzed in each village respectively by the method of least squares, linear equation after entering into MS Excel sheet.

Results: Study included 5,114 patients with fever, out of which $34 \%$ were of 18-30 years. In few villages, there was downward trend of patients with fever and in some villages, an upward trend of patients with fever was observed. Majority of patients with fever $(2,795)$ were observed in August 2019 (12.29\%) and September 2019 (12.33\%).

Conclusion: The number of patients with fever showed a downward and upward trend swings during the study period. Implementation of health education regarding the prevention of the vector-borne diseases is warranted. It emphasizes the importance of visiting a healthcare center in case of a fever. The study will give a better insight into the epidemiology of febrile illnesses. This will further help the health planners to allocate the resources in the most appropriate way.

Keywords: Febrile IIIness, Fever, Karnataka, Trend.

The Journal of Medical Sciences (2020): 10.5005/jp-journals-10045-00144
\end{abstract}

\section{INTRODUCTION}

Fever or pyrexia is a physiological disorder in which temperature is risen above homeostasis condition. Febrile illness is the most common public health problem affecting most people in developing world. Having a fever is a sign that something out of the ordinary is going on inside the body.

Various infectious diseases are caused due to virus and bacteria. Fever results due to the action on cerebral-regulating centers by substances which are released by the damaged cells which in turn causes elevation of the body temperature. 'Some pathogenic microorganisms do not show any pyrogens.

When fever presents without localizing features, this becomes a major problem to the healthcare workers and the health system. ${ }^{2}$ Therefore, it is important to understand fever and febrile response, as it is vital for the diagnosis, treatment, and follow-up of various diseases. This helps in identifying the trends timely, thus interventional strategies can be implemented accordingly.

\section{Materials and Methods}

A descriptive study was conducted in field practice area of a tertiary care hospital, Bengaluru. Three villages were under this health center, namely Huluvenahalli, Chunchanakuppe, and Kolur. After obtaining the permissions from the concerned authorities, the records of the outpatient department (OPD) patients were taken and a retrospective record review was conducted. Patients with fever who reported to the center were analyzed from January 2019 to September 2019. All the patients were aged above 18 years.
${ }^{1-5}$ RajaRajeswari Medical College and Hospital, Bengaluru, Karnataka, India

Corresponding Author: Krithika Talari Thyagaraj, RajaRajeswari Medical College and Hospital, Bengaluru, Karnataka, India, Phone: +91 8880821211, e-mail: drkrithi2018@yahoo.com

How to cite this article: Thyagaraj KT, Patle BS, AC Shyam, et al. Analysis of Trends of Fever in the Field Practice Area of a Tertiary Care Hospital, Bengaluru: A Retrospective Data Review. J Med Sci 2020;6(1):8-13.

Source of support: Nil

Conflict of interest: None

A total of 10,627 visited the OPD. Out of which, 5,114 patients were reported of fever. Patients with fever were subjected to investigations for Venereal Disease Research Laboratory (VDRL), hepatitis B surface antigen ( $\mathrm{HbsAg}$ ), and blood smear tests for malaria parasite, Widal test, urine routine, sputum microscopy, and platelet count. The trends were analyzed in each village by the linear equation. The data were analyzed using MS Excel sheet. The trends of fever were analyzed in each village by using the time series analysis: method least squares, by using the linear equation $(Y=a+b X)$.

The secular trend line $(Y)$ is defined as: $Y=a+b X$, where $Y$ is the predicted value of the dependent variable, $a$ is the $Y$-axis intercept [the height of the line above origin (when $X=0, Y=a$ )], $b$ is the slope of the line (the rate of change in $Y$ for a given change in $X$ ), and $X$ is the independent variable (in this case, it is time). 
When $b$ is positive, the slope is upwards, and when $b$ is negative, the slope is downwards.

To estimate the constants $a$ and $b$, the following two equations have to be solved simultaneously:

$$
\begin{gathered}
\sum Y=n a+b \sum X \\
\sum X Y=a \sum X+b \sum X^{2}
\end{gathered}
$$

To simplify the calculations, if the midpoint of the time series is taken as origin, then the negative values in the first half of the series balance out the positive values in the second half so that $\sum X=0$. In this case, the above two normal equations will be as follows:

$$
\begin{gathered}
\sum Y=n a \\
\sum X Y=b \sum X^{2} \\
\text { Since } \sum Y=n a \\
a=\sum \frac{Y}{n}
\end{gathered}
$$$$
\text { Since, } \sum X Y=b \sum X^{2}
$$

\section{Results}

Out of total OPD patients (January-September 2019) reported at the center, 5,114 were reported of fever. These were further subjected for investigations. In few villages, there was a downward trend of fever and in some villages, an upward trend of fever was observed. In the months of August and September, it was high with $12.29 \%$ and $12.33 \%$, and least in January (9.54\%). VDRL-positive patients were observed higher in July (5\%) and least in February (2\%). The HbsAg-positive patients were observed in July with $4.9 \%$ and in February with $2 \%$. Widal-positive patients were observed was high in the month of July (0.8\%) and September (0.6\%) and least in May (0.2\%) and March (0.1\%). Urine-routine-positive patients were observed in March (8\%), May (10\%), July (9\%), September (7.8\%), and January (6\%). ${ }^{3}$ Patients with dengue were seen in the month of July, August, and September with 0.8, 0.9, and 0.6\% and least observed in April with $0.2 \% .{ }^{4}$ In the months of September, August, and June, about 29,24, and $27 \%$ blood smears for malaria parasite were done, respectively, and least was observed in April with 5.3\%.

In Figure 1, age-wise distribution of patients with fever depicts that majority (34.4\%) of the study subjects belong to the age group of $18-30$ years, followed by $21.6 \%$ of the study subjects belonged to age group $41-50$ years.

In Figure 2, gender-wise distribution of patients with fever depicts that $59.8 \%$ are males and $40.2 \%$ are females.

Figure 3, maximum number of blood smear tests for patients with malaria was done in June and September. VDRL-positive patients were observed higher in July (5\%) and least in February (2\%). The HbsAg-positive patients were observed in July with $4.9 \%$ and in February with $2 \%$. Widal-positive patients were observed high in the months of July $(0.8 \%)$ and September $(0.6 \%)$ and least in May (0.2\%) and March (0.1\%). Urine routine-positive patients were observed in March (8\%), May (10\%), July (9\%), September (7.8\%), and January (6\%). Patients with dengue were seen in the months of July, August, and September with 0.8, 0.9, and 0.6\% and least was observed in April with $0.2 \%$ (Tables 1 to 4 ).

\section{Trends in Fever}

Patients with fever from Huluvenahalli showed downward trend from (11.4-10.7\%) and Chunchanakuppe (11.3-10.9\%) from January to September 2019. There was a significant upward trend of patients with fever observed in Kolur (8.7-13.5\%) from January to September 2019.

In Figure 4, the patients from Hulluvenahalli village showed downward trend from 11.4 to $10.7 \%$. The patients from Chunchanakuppe village showed downward trend from 11.3 to $10.9 \%$. There was a significant upward trend of patients with fever observed in Kolur village (8.7-13.5\%) from January to September 2019.

\section{Discussion}

The record based data showed that out of 5,114 patients with fever, majority were observed in August 2019 (12.29\%) and September 2019 (12.33\%). The seasonal pattern should alarm the clinicians to consider malaria and dengue, which are observed during monsoon season and postmonsoon season. ${ }^{5}$ The blood smears tested were observed almost throughout the study duration. This was the same during the year 2018. A similar analysis from a healthcare center in Rajasthan showed both dengue and malaria follow the same seasonal pattern in 2 years. ${ }^{6}$ There were a greater number of male patients (59.8\%) compared with that of female patients $(40.2 \%)$ in the current study. ${ }^{7}$ Similarly in the study done by Jain ${ }^{8}$ also showed male patients were more than female patients. Fever being the most common presentation in the current study. A study was done by Mohan et al., ${ }^{9}$ where fever being the most common symptom. In the current study, gastrointestinal symptoms were observed, of which abdomen pain and nausea/vomiting were commonly observed in the study population. This was observed in a similar study done by Jain, ${ }^{8}$ where gastrointestinal symptoms were more prevalent, of which abdominal pain was present in $42.5 \%$ and nausea/vomiting in $28.7 \%$ of the study population. In the present study, patients with dengue were observed in the month of July, August, and September with $0.8,0.9$, and $0.6 \%$. A similar study done by Kumar et al. $^{10}$ showed that maximum number patients with dengue were examined in the months of August and September. Early evaluation of the febrile traveler, a high degree of suspicion

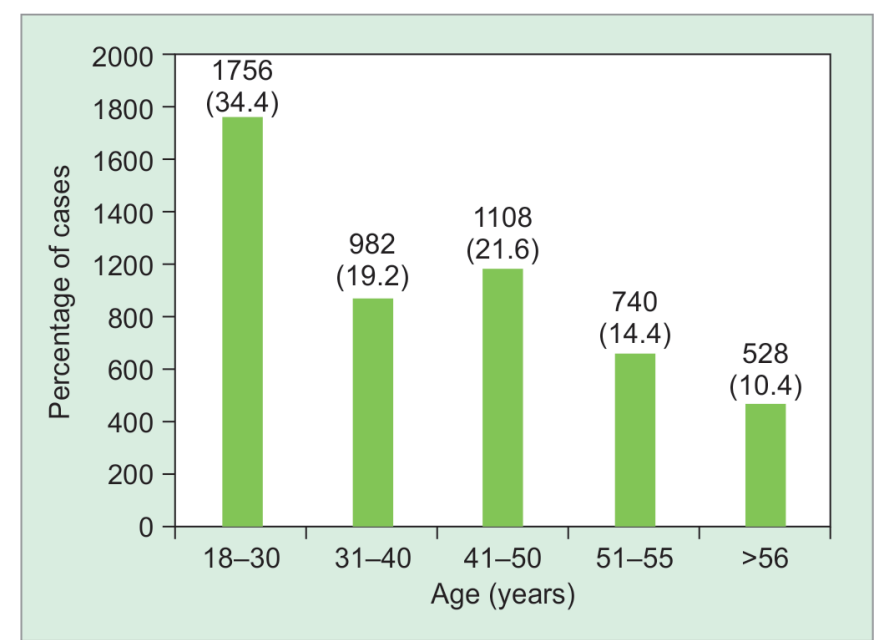

Fig. 1: Age-wise distribution of patients with fever 
of malaria, ${ }^{11,12}$ rapid and accurate diagnosis, and appropriate antimalarial therapy are essential for the patient's recovery. The overall proportion of patients with fever showed an upward and

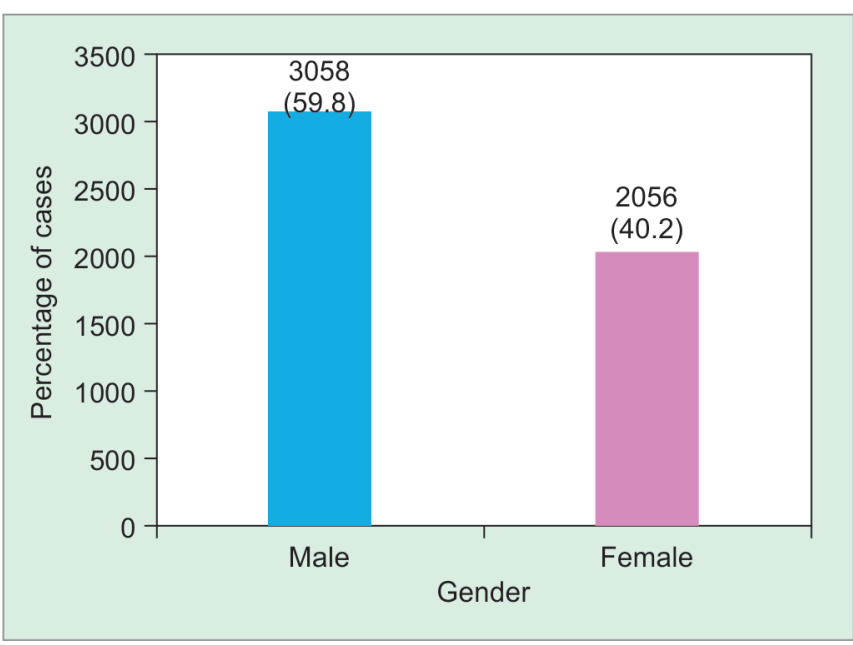

Fig. 2: Gender-wise distribution of patients with fever downward trend. Similar results were observed by the study done by Sharma et al. ${ }^{13}$ The female attendance for seeking healthcare with fever as a chief complaint observed an upward trend.

The burden of various diseases (emerging and re-emerging) could be reduced if we take measure to detect the changes in the trend through the implementation of the surveillance programs in the country. These programs have been implemented in other countries.

\section{CONCLUSION}

It was observed that the number of patients with fever showed downward and upward trend swings during this study period of January 2019 to September 2019. It is necessary to conduct further studies over a longer period of time to look for seasonal and cyclical variations in the occurrences of different patients with fever to institute preventive and control measures.

The healthcare system needs to be strengthened to study the seasonal variations of the diseases over a long period of time. This will further help the health planners to allocate the resources in the most appropriate way.

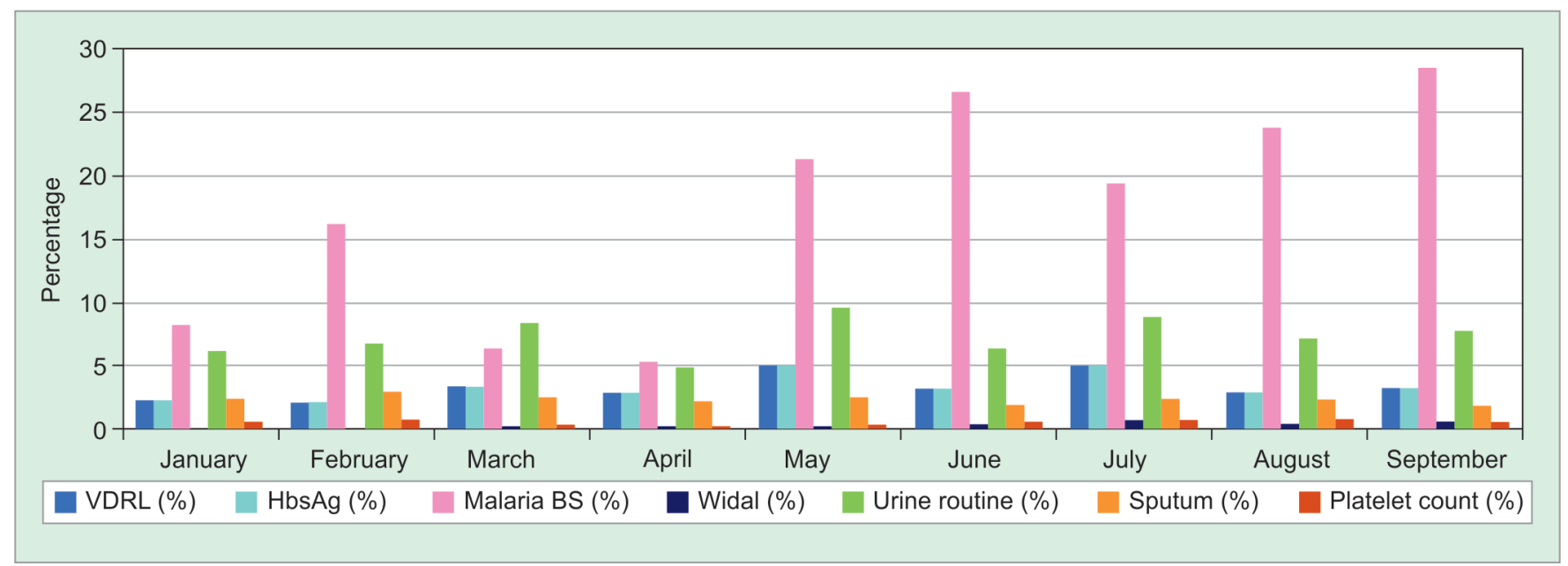

Fig. 3: Month-wise distribution of patients with fever

Table 1: Month-wise distribution of patients with fever. $N=5,114$

\begin{tabular}{|c|c|c|c|c|c|c|c|}
\hline $\begin{array}{l}\text { Investigations } \\
(N=10,627 \text { OPD } \\
\text { patients) }\end{array}$ & VDRL (\%) & $H b s A g(\%)$ & Malaria BS (\%) & Widal (\%) & $\begin{array}{l}\text { Urine routine } \\
\text { (\%) }\end{array}$ & Sputum (\%) & Platelet (\%) \\
\hline January $(n=1,227)$ & $28(2 \%)$ & $28(2 \%)$ & $40(8 \%)$ & - & $76(6 \%)$ & $31(3 \%)$ & $8(1 \%)$ \\
\hline February $(n=1,158)$ & $25(2 \%)$ & $25(2 \%)$ & $80(16 \%)$ & - & $79(7 \%)$ & $35(3 \%)$ & $10(0.8 \%)$ \\
\hline $\operatorname{March}(n=1,179)$ & $40(3 \%)$ & $40(3 \%)$ & $40(6 \%)$ & $2(0.2 \%)$ & $99(8 \%)$ & $30(3 \%)$ & $5(0.4 \%)$ \\
\hline April $(n=1,118)$ & $33(3 \%)$ & $33(3 \%)$ & $30(5 \%)$ & $3(0.3 \%)$ & $55(5 \%)$ & $25(2 \%)$ & $3(0.2 \%)$ \\
\hline May $(n=1,028)$ & $51(5 \%)$ & $51(5 \%)$ & $120(21 \%)$ & $2(0.2 \%)$ & 99 (10\%) & $28(3 \%)$ & $4(0.3 \%)$ \\
\hline June $(n=1,190)$ & $38(3 \%)$ & $38(3 \%)$ & $150(27 \%)$ & $5(0.4 \%)$ & $78(7 \%)$ & $24(2 \%)$ & $8(1 \%)$ \\
\hline July $(n=1,132)$ & $56(5 \%)$ & $56(5 \%)$ & $110(19 \%)$ & $9(0.8 \%)$ & $102(9 \%)$ & $28(2 \%)$ & $9(0.8 \%)$ \\
\hline August $(n=1,220)$ & $36(3 \%)$ & $36(3 \%)$ & $150(24 \%)$ & $5(0.4 \%)$ & $88(7 \%)$ & $29(2 \%)$ & $10(0.8 \%)$ \\
\hline $\begin{array}{l}\text { September } \\
(n=1,375)\end{array}$ & $45(3 \%)$ & $45(3 \%)$ & $180(29 \%)$ & $9(0.7 \%)$ & $107(8 \%)$ & $27(2 \%)$ & $9(0.6 \%)$ \\
\hline
\end{tabular}




\begin{tabular}{|c|c|c|c|c|c|}
\hline Period 2019 & $Y$ & $x$ & $x^{2}$ & $X Y$ & TREND $Y=a+b X$ \\
\hline January & 64 & -4 & 16 & -256 & 92.2 \\
\hline February & 97 & -3 & 9 & -291 & 91.65 \\
\hline March & 109 & -2 & 4 & -218 & 91.1 \\
\hline April & 93 & -1 & 1 & -93 & 90.55 \\
\hline May & 108 & 0 & 0 & 0 & 90 \\
\hline June & 94 & 1 & 1 & 94 & 89.45 \\
\hline July & 91 & 2 & 4 & 182 & 88.9 \\
\hline August & 67 & 3 & 9 & 201 & 88.35 \\
\hline September & 87 & 4 & 16 & 348 & 87.8 \\
\hline Total & $\sum Y=810$ & $\sum X=0$ & $\sum X^{2}=60$ & $\sum X Y=-33$ & $\sum Y=810$ \\
\hline
\end{tabular}

$\mathrm{Y}=a+b X$

$\sum Y=n a+b \sum X^{2}$

$\sum X Y=a \sum X+b \sum X^{2}$

$a=\sum \frac{Y}{n}$

$a=\sum \frac{Y}{n}=\frac{810}{9}=90$

$a=90$

$b=\frac{\sum X Y}{\sum X^{2}}$

$b=\frac{-33}{60}=-0.55$

$b=-0.55$

Table 3: Chunchanakuppe village: showed a downward trend

\begin{tabular}{|c|c|c|c|c|c|}
\hline Period 2019 & $Y$ & $x$ & $x^{2}$ & $X Y$ & TREND $Y=a+b X$ \\
\hline January & 51 & -4 & 16 & -204 & 71.74 \\
\hline February & 55 & -3 & 9 & -165 & 71.38 \\
\hline March & 96 & -2 & 4 & -192 & 70.98 \\
\hline April & 84 & -1 & 1 & -84 & 70.6 \\
\hline May & 86 & 0 & 0 & 0 & 70.22 \\
\hline June & 83 & 1 & 1 & 83 & 69.84 \\
\hline July & 58 & 2 & 4 & 116 & 69.46 \\
\hline August & 53 & 3 & 9 & 159 & 69.08 \\
\hline September & 66 & 4 & 16 & 264 & 68.7 \\
\hline Total & $\sum Y=632$ & $\sum X=0$ & $\sum X^{2}=60$ & $\sum X Y=-23$ & $\sum Y=632$ \\
\hline
\end{tabular}

where

$Y=a+b X$

$\sum Y=n a+b \sum X^{2}$

$\sum X Y=a \sum X+b \sum X^{2}$

$a=\sum \frac{Y}{n}$

$a=\sum \frac{Y}{n}=\frac{632}{9}=70.22$

$b=\frac{\sum X Y}{\sum X^{2}}$

$b=\frac{-23}{60}=-0.38$

$b=-0.38$ 
Table 4: Kolur village: showed an upward trend

\begin{tabular}{|c|c|c|c|c|c|}
\hline Period 2019 & $Y$ & $x$ & $x^{2}$ & $X Y$ & TREND $Y=a+b X$ \\
\hline January & 40 & -4 & 16 & -160 & 53.74 \\
\hline February & 26 & -3 & 9 & -78 & 57.36 \\
\hline March & 85 & -2 & 4 & -170 & 60.98 \\
\hline April & 79 & -1 & 1 & -79 & 64.6 \\
\hline May & 87 & 0 & 0 & 0 & 68.22 \\
\hline June & 90 & 1 & 1 & 90 & 71.84 \\
\hline July & 77 & 2 & 4 & 154 & 75.46 \\
\hline August & 60 & 3 & 9 & 180 & 79.08 \\
\hline September & 70 & 4 & 16 & 280 & 82.7 \\
\hline Total & $\sum Y=614$ & $\sum X=0$ & $\sum X^{2}=60$ & $\sum X Y=217$ & $\sum Y=614$ \\
\hline
\end{tabular}

$Y=a+b X$

$\sum Y=n a+b \sum X^{2}$

$\sum X Y=a \sum X+b \sum X^{2}$

$a=\sum \frac{Y}{n}$

$a=\sum \frac{Y}{n}=\frac{614}{9}=68.22$

$a=90$

$b=\frac{\sum X Y}{\sum X^{2}}$

$b=\frac{217}{60}=3.62$

$b=3.62$

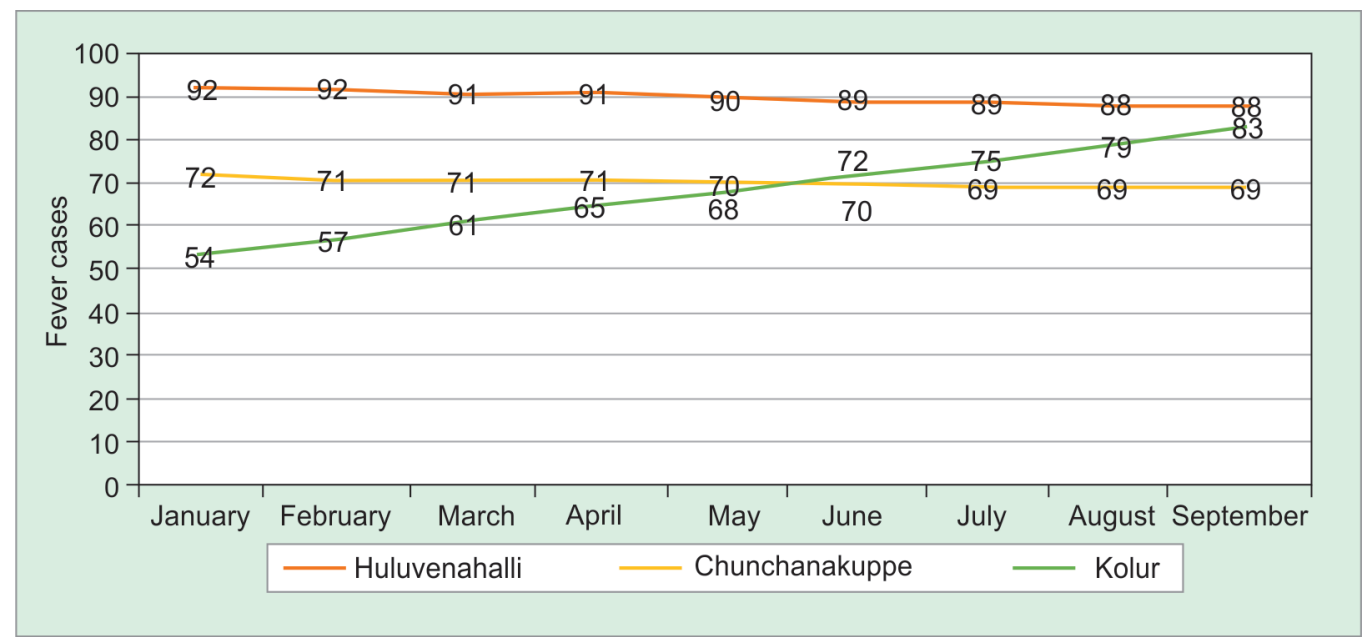

Fig. 4: Trends of fever in villages

\section{References}

1. González Plaza JJ, Hulak N, Zhumadilov Z, et al. Fever as an important resource for infectious diseases research. Intracta Rare Disea Res 2016;5(2):97-102. DOI: 10.5582/irdr.2016.01009.

2. Crump JA, Newton PN, Baird SJ, et al. Febrile illness in adolescents and adults Holmes KK, Bertozzi S, Bloom BR, et al., ed. Major Infectious Diseases. 3rd ed., ch. 14, Washington (DC): The International Bank for Reconstruction and Development/The World Bank; 2017. Available from: https://www.ncbi.nlm.nih.gov/books/NBK525177/10.1596/9781-4648-0524-0_ch14.

3. Sulekha C, Kumar S, Philip J. Gullian-barre syndrome following dengue fever. Indian Pediatr 2004;41:948-952.

4. Rachel D, Rajamohanan, Philip AZ. A study of clinical profile of dengue fever in Kollam, Kerala, India. Dengue Bull 2005;29:197-202.

5. Ogoina D. Fever, fever patterns and diseases called 'fever'--a review. J Infect Pub Health 2011;4(3):108-124. DOI: 10.1016/j.jiph.2011. 05.002 
6. Sharma R, Ahmed S, Gupta S. Comparative evaluation of seasonal fevers in last 2 years at a tertiary care hospital in North India. Int J Curr Microbiol App Sci 2014;3(7):631-634.

7. Padbidri VS, Adhikari P, Thakare JP, et al. The 1993 epidemic of dengue fever in Mangalore, Karnataka State, India. Southeast Asian J Trop Med Public Health 1995;26:699-704.

8. Jain D, Rajput R, PathakV, et al. Changing trends in clinical presentation and biochemical spectrum of dengue fever: an observation of a tertiary care centre, arch. Clin Infect Dis 2017;12(3):e62221. DOI: 10.5812/archcid.62221.

9. Mohan DK, Shiddappa M, Dhananjaya M. A study of clinical profile of dengue fever in a tertiary care teaching hospital. Sch J App Med Sci 2013;1:280-282.
10. Kumar A, Rao CR, Pandit V, et al. Clinical manifestations and trend of dengue cases admitted in a tertiary care hospital, Udupi district, Karnataka. Indian J Community Med 2010;35(3):386-390. DOI: 10.4103/0970-0218.69253.

11. Suh KN, Kain KC, Keystone JS. Malaria. CMAJ 2004;170(11):1693-1702. DOI: 10.1503/cmaj.1030418.

12. Committee to Advise on Tropical Medicine and Travel (CATMAT) Canadian recommendations for the prevention and treatment of malaria among international travelers 2000. Can Commun Dis Rep 2000;26(S2):1-42.

13. Sharma P, Singh M, Gandhi MK, et al. Seasonal trend of fever cases seeking health care services at a tertiary care centre- an audit of retrospective data from sub-Himalayan region. J Evolution Med Dent Sci 2018;7(15):1862-1867. DOI: 10.14260/jemds/2018/420. 